\title{
Digestion and Absorption of Sugars and Sugar Substitutes in Rat Small Intestine
}

\author{
Yoshimitsu TsujI, Kazuhiko YamadA, Norimasa HosoyA, ${ }^{1}$ \\ and Sachiko MORIUCHI ${ }^{2}$ \\ ${ }^{1}$ Department of Nutrition, School of Health Sciences, \\ Faculty of Medicine, The University of \\ Tokyo, Bunkyo-ku, Tokyo 113, Japan \\ ${ }^{2}$ Department of Food and Nutrition, School of \\ Home-Economics, Japan Women's University, \\ Bunkyo-ku, Tokyo 112, Japan
}

(Received August 30, 1985)

\begin{abstract}
Summary The bioavailability of newly developed sugar substitutes was observed by measuring the transmural potential difference $(\Delta \mathrm{PD})$ evoked by $\mathrm{Na}^{+}$-dependent active trasport of glucose, which is supposed to be produced by the hydrolysis of sugar substitutes. $\triangle \mathrm{PD}$ was measured using everted intestinal sac prepared from jejunum of adult rats and compared with the digestibility of sugar substitutes in the mucosal homogenate of everted sac.

$\triangle \mathrm{PDs}$ evoked by glucose, maltose or maltosylfructose had almost the same levels, however, the $\triangle \mathrm{PD}$ evoked by sucrose was a little lower. $\triangle \mathrm{PD}$ evoked by maltitol or palatinose were low, and $\triangle \mathrm{PDs}$ evoked by fructooligosaccharides were negligible. The hydrolyzing activities of these sugars and sugar substitutes by the mucosal homogenate were correlated with the $\triangle$ PDs. A significant positive correlation was observed between $\Delta \mathrm{PD}_{\max }$ of various sugars and sugar substitutes and the $V_{\max }$ of their corresponding hydrolyzing activities. Also, a significant positive correlation was observed between $K_{\mathrm{t}}$ and $K_{\mathrm{m}}$ values of these sugars.

These results suggest that the absorption of sugar substitutes is dependent on digestibility by membrane digestive enzymes.
\end{abstract}

Key Words sugar substitutes, disaccharidase activity, transmural potential difference, small intestine

Many sugar substitutes have recently been developed as artificial sweeteners for the prevention of dental caries, obesity and diabetes mellitus (1-3). The digestibility of these sugar substitutes by intestinal disaccharidases has been well investigated.

1 辻 義光, 山田和彦, 細谷憲政, ${ }^{2}$ 森内幸子 
Previous studies in our laboratory have shown that maltosylfructose and maltotriosylfructose, which are known as coupling sugars, are hydrolyzed by maltase and sucrase in the brush border membranes, their hydrolyzing activities being comparable to those of maltose $(4,5)$. Palatinose, in which glucose is bound to fructose by an $\alpha-1,6$-linkage, was hydrolyzed by the active site of isomaltase of the sucraseisomaltase complex (6). Maltitol, a sugar alcohol, is slowly hydrolyzed by maltase, but not by sucrase(7). Fructo-oligosaccharides were hydrolyzed by intestinal disaccharidases $(8)$ to only a small extent.

However, the following absorptive process of these sugar substitutes has not been investigated. Naturally occurring oligosaccharides are considered to be subjected to the terminal digestive step by the membrane digestive enzymes, and the released monosaccharide, glucose, to be absorbed by carrier-mediated steps. A net mucosal-serosal flux of glucose is accompanied by that of $\mathrm{Na}^{+}$, which induces a transmural potential difference $(\triangle \mathrm{PD})(9)$. Therefore, the transmural potential difference $(\triangle \mathrm{PD})$ evoked by $\mathrm{Na}^{+}$-dependent active transport of glucose, which was supposed to be produced by the hydrolysis of sugar substitutes, was measured using everted intestinal sac and compared with the digestibilities of the latter.

\section{MATERIALS AND METHODS}

1. Animals. Male rats of Wistar strain, each weighing about $250 \mathrm{~g}$, were given a standard labolatory chow (Oriental Yeast Co.) and water ad libitum. The rats were killed by decapitation at between $13: 00$ and $15: 00 \mathrm{~h}$ without fasting.

2. Preparation of isolated everted intestinal segments. The small intestine from the ligament of Treitz to the ileocecal junction was quickly excised, and the proximal portion of the jejunum was removed. The jejunal segment $(3 \mathrm{~cm}$ in length) was rinsed with a standard buffer solution (composition described below), everted and fixed over a small fenestrated polyethylene tube $(5 \mathrm{~mm}$ outer diameter). The inside of the tube was filled with the standard solution and the mucosal side of the intestine was immersed in $9 \mathrm{ml}$ of bathing solution (the standard buffer solution). The bathing solution was continuously aerated and its temperature was kept constant at $37^{\circ} \mathrm{C}$ during the experiments. The standard buffer solution had the following composition (mM); $\mathrm{Na}_{2} \mathrm{SO}_{4}, 50$; mannitol, $160 ; \mathrm{CaSO}_{4}, 1.5 ; \mathrm{MgSO}_{4}, 1.0$; $\mathrm{KH}_{2} \mathrm{PO}_{4}, 0.5 ; \mathrm{K}_{2} \mathrm{HPO}_{4}, 2.0(\mathrm{pH} 7.4)(10)$.

3. Recording of the transport-related increments in the transumural potential. $\quad \mathrm{PD}$ was led out by connecting calomel half cells to the mucosal and serosal medium by means of $2 \%$ agar containing $3 \mathrm{M} \mathrm{KCl}$ and was recorded by a high-sensitivity DC pen-recorder (National VP 6541A)(11). After the spontaneous $\triangle \mathrm{PD}$ had attained a steady level, a certain small amount of sugar dissolved in $1 \mathrm{ml}$ of standard solution was rapidly injected into $9 \mathrm{ml}$ of mucosal medium. The final concentration of sugar was varied by changing the amount of the sugar to be added. Sugars examined were D-glucose, maltose, maltitol, maltotriose, maltotriitol, sucrose, maltosylfructose, maltotriosylfructose, isomaltose, palatinose, trehalulose, 
kestose and nystose.

4. Assays of hydrolyzing activities of various sugars and sugar substitutes, and protein determination. After the measurement of $\triangle \mathrm{PD}$ induced by sugars, each segment was homogenized with 9 volumes of $10 \mathrm{~mm}$ potassium phosphate buffer ( $\mathrm{pH}$ 7.0) and was stored at $-20^{\circ} \mathrm{C}$ until use. An aliquot of the homogenate was used for the assays. Hydrolyzing activities of various sugars were determined by the method of Dahlqvist (12). Substrate concentration was $10 \mathrm{~mm}$ in the standard buffer solution. Protein concentration was determined by the method of Lowry et al. using bovine serum albumin as a standard(13). Hydrolyzing activity was expressed as specific activity ( $\mu$ mol-glucose-released/mg-protein $/ \mathrm{h})$. Statistical analysis was carried out by Student's $t$-test.

5. Chemicals. Glucose and sucrose were purchased from Wako Pure Chemical Industries Ltd. Maltose, isomaltose, maltotriose, maltitol, maltotriitol, maltosylfructose and maltotriosylfructose were provided by Hayashibara Co., Ltd. Palatinose and trehalulose were provided by Mitsui Sugar Co., Ltd. Kestose and nystose were provided by Meiji Seika Co., Ltd. Glucose oxidase was obtained from Worthington Biochemical Co. Other reagents were analytical grade chemicals.

\section{RESULTS}

1. Transmural potential differences $(\triangle P D)$ induced by various sugars and sugar substitutes, and their hydrolyzing activities in rat intestine

The sugar-evoked potential differences $(\triangle \mathrm{PD})$, when various sugars and sugar substitutes were added to the mucosal side of the small intestine, were observed as the increments of mucosal negativity in rat intestine, and after the measurement of the potential difference of everted intestine, the hydrolyzing activities of various sugars and sugar substitutes were assayed (Table 1). $\triangle$ PDs evoked by maltose and isomaltose were of almost the same level as that evoked by glucose, however, the $\triangle \mathrm{PD}$ evoked by sucrose was about one-half of that evoked by glucose, whereas $\triangle \mathrm{PD}$ evoked by trehalulose, which is a recently developed $\alpha-1,4$ linked disaccharide of glucose and fructose, was one-half of that evoked by sucrose. $\triangle$ PDs evoked by palatinose and maltitol were low. $\triangle \mathrm{PDs}$ evoked by maltosylfructose and maltotriosylfructose were similar to that by maltose, the $\triangle \mathrm{PD}$ evoked by maltotriose being the highest. However, $\triangle \mathrm{PD}$ s evoked by fructo-oligosaccharides, which were not hydrolyzed by intestinal disaccharidases, were negligible.

On the other hand, hydrolyzing activity was highest for maltose, and those for maltotriose, maltotriitol, isomaltose, maltosylfructose and maltotriosylfructose were of similar level and about one-fifth of the maltose hydrolyzing activity. The hydrolyzing activities for sucrose and trehalulose were of the same level, however, those for palatinose and maltitol were much lower than those for sucrose and trehalulose. The hydrolyzing activities of fructo-oligosaccharides were not detectable. The hydrolyzing activities of these sugars and sugar substitutes were in good parallel with the results of the $\triangle \mathrm{PD}$ s evoked by various sugars. 
Table 1. Transmural potential difference $(\Delta \mathrm{PD})$ induced by sugars and sugar substitutes and their hydrolyzing activities in rat jejunum.

Results are expressed as means $\pm \mathrm{SE}$ of 14 rats. $\triangle \mathrm{PD}$ and hydrolyzing activities were measured at the concentration of $10 \mathrm{~mm}$ in each substrate.

\begin{tabular}{lcc}
\hline \multicolumn{1}{c}{ Sugars } & PD $(\mathrm{mV})$ & Hydrolyzing activity $^{\mathrm{a}}$ \\
\hline Glucose & $1.90 \pm 0.12$ & \\
Maltose & $2.16 \pm 0.13$ & $51.5 \pm 3.84$ \\
Maltitol & $0.05 \pm 0.02$ & $0.37 \pm 0.09$ \\
Maltotriose & $2.60 \pm 0.35$ & $12.7 \pm 0.41$ \\
Maltotriitol & $1.66 \pm 0.18$ & $13.8 \pm 1.08$ \\
Sucrose & $1.15 \pm 0.12$ & $4.15 \pm 0.39$ \\
Maltosylfructose & $2.07 \pm 0.32$ & $11.3 \pm 0.74$ \\
Maltotriosylfructose & $2.24 \pm 0.31$ & $9.57 \pm 0.48$ \\
Isomaltose & $2.03 \pm 0.27$ & $10.1 \pm 0.60$ \\
Palatinose & $0.28 \pm 0.04$ & $0.98 \pm 0.05$ \\
Trehalulose & $0.57 \pm 0.13$ & $3.03 \pm 0.19$ \\
Kestose & N.D. & N.D. \\
Nystose & N.D. & N.D. \\
\hline
\end{tabular}

${ }^{\mathrm{a}} \mu \mathrm{mol}$-glucose-released/mg protein/h. N.D., not detectable.

Table 2. Kinetic prameters of hydrolysis of sugars and sugar substitutes in rat jejunum.

Results are expressed as means $\pm \mathrm{SE}$ of 5 rats. $K_{\mathrm{m}}$ and $V_{\max }$ are estimated by measuring at different sugar concentrations according to Lineweaver-Burk plot.

\begin{tabular}{lrr}
\hline \multicolumn{1}{c}{ Sugars } & \multicolumn{1}{c}{$K_{\mathrm{m}}(\mathrm{mM})$} & \multicolumn{1}{c}{$V_{\max }{ }^{\mathrm{a}}$} \\
\hline Maltose & $1.58 \pm 0.05$ & $55.90 \pm 10.00$ \\
Maltitol & $62.53 \pm 4.68$ & $3.17 \pm 0.38$ \\
Maltotriose & $1.38 \pm 0.19$ & $32.59 \pm 2.54$ \\
Maltotriitol & $2.44 \pm 0.67$ & $35.22 \pm 5.81$ \\
Sucrose & $17.46 \pm 0.37$ & $11.72 \pm 1.28$ \\
Maltosylfructose & $1.69 \pm 0.17$ & $28.36 \pm 4.27$ \\
Maltotriosylfructose & $1.39 \pm 0.08$ & $39.97 \pm 6.21$ \\
Isomaltose & $4.52 \pm 0.68$ & $14.36 \pm 1.00$ \\
Palatinose & $3.62 \pm 0.58$ & $1.34 \pm 0.23$ \\
Trehalulose & $2.45 \pm 0.14$ & $4.41 \pm 0.41$ \\
\hline
\end{tabular}

${ }^{\text {a }} \mu$ mol-glucose-released $/ \mathrm{mg}$ protein $/ \mathrm{h}$.

\section{Kinetic parameters of hydrolysis of various sugars in rat intestine}

The hydrolyzing activites were determined for various sugars and sugar substitutes for different substrate concentrations. From these, the Michaelis constant $\left(K_{\mathrm{m}}\right)$ and the maximal velocity $\left(V_{\max }\right)$ for various sugars and sugar 
Table 3. Kinetic parameters of sugar transport in rat jejunum.

Results are expressed as means $\pm \mathrm{SE}$ of 5 rats. $K_{\mathrm{t}}$ and $\Delta \mathrm{PD}_{\max }$ are estimated by measuring at different sugar concentrations according to Lineweaver-Burk plot.

\begin{tabular}{lrc}
\hline \multicolumn{1}{c}{ Sugars } & \multicolumn{1}{c}{$K_{\mathrm{t}}(\mathrm{mM})$} & $\Delta \mathrm{PD}_{\max }(\mathrm{mV})$ \\
\hline Glucose & $9.36 \pm 0.38$ & $4.04 \pm 0.76$ \\
Maltose & $4.76 \pm 0.66$ & $3.56 \pm 0.58$ \\
Maltotriose & $4.46 \pm 0.31$ & $4.07 \pm 0.96$ \\
Maltotriitol & $8.37 \pm 0.62$ & $2.60 \pm 0.17$ \\
Sucrose & $18.44 \pm 0.61$ & $2.62 \pm 0.51$ \\
Maltosylfructose & $6.75 \pm 0.24$ & $2.42 \pm 0.21$ \\
Maltotriosylfructose & $5.82 \pm 0.32$ & $3.12 \pm 0.64$ \\
Isomaltose & $5.89 \pm 0.34$ & $2.77 \pm 0.54$ \\
Palatinose & $10.56 \pm 1.44$ & $0.45 \pm 0.14$ \\
Trehalulose & $8.56 \pm 1.50$ & $0.98 \pm 0.31$ \\
\hline
\end{tabular}

substitutes were determined by the graphical method of the Lineweaver-Burk plot (Table 2). The $K_{\mathrm{m}}$ value for maltotriose was the lowest, which was followed by that for maltotriosylfructose, maltose, maltosylfructose and sucrose, while that for maltitol, which was hydrolyzed to only a small extent by intestinal hydrolase, was the highest. On the other hand, the $V_{\max }$ value for maltose was the highest, which was followed by that for maltotriosylfructose, maltotriitol and maltotriose, while that for trehalulose, palatinose and maltitol was very low.

\section{Kinetic parameters of sugar transport in rat intestine}

The sugar-evoked potential difference is thought to exhibit a Michaelis-Menten like relationship with sugar concentrations. Therefore, in order to examine whether there are some changes of kinetic properties, such as sugar concentration giving half maximal $\triangle \mathrm{PD}\left(K_{\mathrm{t}}\right)$ and maximal potential difference $\left(\Delta \mathrm{PD}_{\max }\right)$, of the transport of various sugars and sugar substitutes, $\triangle \mathrm{PD}$ s were measured in the presence of various concentrations of sugars and sugar substitutes. As shown in Table 3, the $K_{\mathrm{t}}$ value for maltotriose was the lowest, followed by that for maltose, maltotriosylfructose, isomaltose, the $K_{\mathrm{t}}$ for glucose being higher than that for maltose, while those for trehalulose, palatinose and sucrose showed high values. On the other hand, $\triangle \mathrm{PD}_{\max }$ values for maltose, maltotriose, maltotriosylfructose and glucose were high, but those for trehalulose and palatinose were low.

\section{Correlation between kinetic parameters of sugar transport and hydrolysis of various sugars}

In order to determine the correlation between sugar transport and the hydrolysis of various sugars, the relationship between kinetic parameters of sugar transport and hydrolysis of sugar substitutes was observed. A highly significant correlation $(r=0.92, p<0.01)$ of the $K_{\mathrm{t}}$ value for sugar transport versus the $K_{\mathrm{m}}$ value 


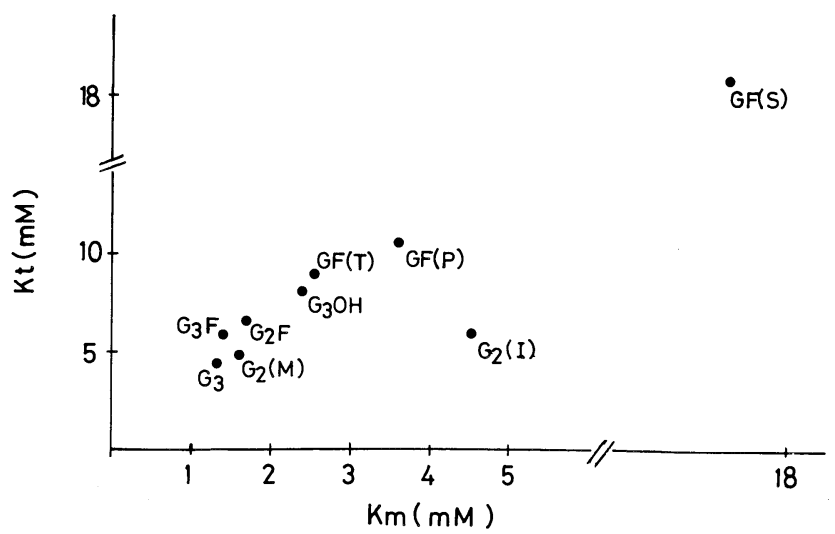

Fig. 1. Relation between $K_{\mathrm{t}}$ of $\Delta \mathrm{PD}$ evoked by sugars and sugar substitutes and $K_{\mathrm{m}}$ of their hydrolyzing activities in rat jejunum. Results are expressed as means of 5 animals at each point. Abbreviations of sugars and sugar substitutes: $G_{2}(M)$, maltose; $\mathrm{G}_{2}(\mathrm{I})$, isomaltose, $\mathrm{G}_{3}$, maltotriose; $\mathrm{G}_{3} \mathrm{OH}$, maltotriitol; $\mathrm{GF}$ (S), sucrose; GF (P), palatinose; GF (T), trehalulose; $G_{2} F$, maltosylfructose; $G_{3} F$, maltotriosylfructose.

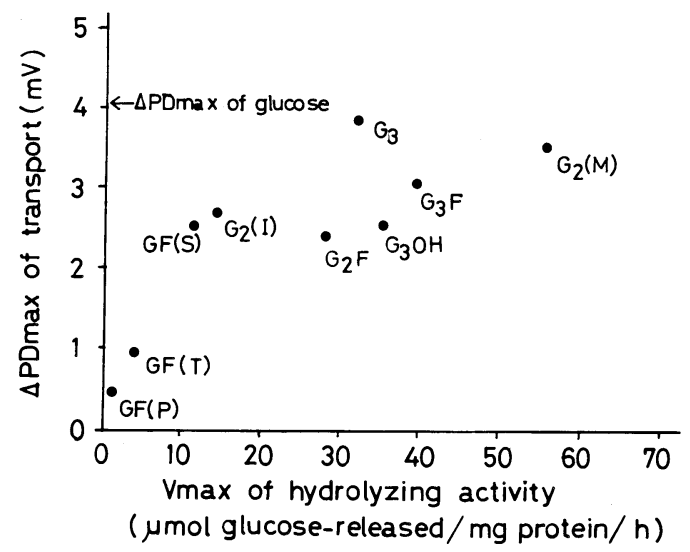

Fig. 2. Relation between $\triangle \mathrm{PD}_{\max }$ evoked by sugars and sugar substitutes and $V_{\max }$ of their hydrolyzing activities in rat jejunum. Results are expressed as means of 5 animals at each point. Abbreviations of sugars and sugar substitutes are the same as in Fig. 1.

for hydrolysis of various sugars was observed (Fig. 1). Furthermore, a significant correlation $(r=0.78, p<0.02)$ between $\Delta \mathrm{PD}_{\max }$ for sugar transport and $V_{\max }$ for hydrolysis of various sugars was also observed (Fig. 2).

\section{DISCUSSION}

In the present study, the bioavailability of sugar substitutes was investigated by 
measuring the transmural potential difference $(\Delta \mathrm{PD})$ evoked by $\mathrm{Na}^{+}$-dependent active transport of glucose, which is supposed to be produced by the hydrolysis of sugar substitutes.

$\triangle$ PDs evoked by various sugar substitutes were well correlated with hydrolyzing activities. Namely, $\triangle \mathrm{PD}$ evoked by sugar substitutes, the hydrolyzing activity of which was high, was large, the latter being small with low hydrolyzing activity. These results were further confirmed by kinetic parameters of sugar transport and sugar hydrolyzing activity. A significant positive correlation was observed between $\triangle \mathrm{PD}_{\max }$ evoked by various sugars and sugar substitutes, and $V_{\max }$ of their hydrolyzing activities. Also, a significant positive correlation was observed between $K_{\mathrm{t}}$ and $K_{\mathrm{m}}$ of sugars and sugar substitutes. These results suggest that the digestion and absorption of sugar substitutes could be dependent on their digestibilities by intestinal membrane digestive enzymes. Sucrose-feeding led to an increase in specific activity of sucrase and also an increase in absorption of constituted monosaccharide from sucrose in the rat (14). Lactase activity, which is very low in adult mammals, is considered to be a limiting step in the overall process of lactose absorption (15). Recently, it has been demonstrated that lactose absorption has a significant linear regression with the lactase activity being manipulated by feeding a starch-containing diet to adult rats $(16,17)$. These results also confirm the decisive role of disaccharidase activity in the digestion of corresponding disaccharides and absorption of constitutional monosaccharides.

On the other hand, hydrolyzing activities of various sugar substitutes by intestinal homogenate after $\triangle \mathrm{PD}$ measurement were in good agreement with previous studies using intesinal homogenate, intestinal brush border membranes and purified sucrase-isomaltase complex (5-7). The technique of $\triangle \mathrm{PD}$ measurement in the present study is simple and reproducible, and we can quickly observe the transport and hydrolysis of sugar substitutes in the same tissue. Thus, the measurement of $\triangle \mathrm{PD}$ evoked by $\mathrm{Na}^{+}$-dependent active transport of glucose using everted intestinal sac is a good tool to evaluate the bioavailability of newly developed sugar substitutes.

\section{REFERENCES}

1) Wang, Y. M., and van Eys, J. (1981): Nutritional significance of fructose and sugar alcohols, in Ann. Rev. Nutr., Vol. 1, ed. by Darby, W. J., Annual Reviews Inc., Palo Alto (U.S.A.), pp. 437-475.

2) Grenby, T. H. (1983): Nutritive sucrose substitutes and dental health, in Developments in Sweeteners, Vol. 2, ed. by Grenby, T. H., Parker, K. J., and Lindley, M. G., Applied Science Publishers, Ltd., London, pp. 51-88.

3) Thiébaud, D., Jacot, E., Schmitz, H., Spengler, M., and Felber, J. P. (1984): Comparative study of isomaltose and sucrose by means of continuous indirect calorimetry. Metabolism, 33, 808-813.

4) Yamada, K., Sasaki, M., Moriuchi, S., and Hosoya, N. (1978): Hydrolysis of glucosylsucrose and maltosyl-sucrose in rat intestinal brush border membrane. Food and 
Nutrition (in Japanese), 31, 267-272.

5) Yamada, K., Goda, T., Hosoya, N., and Moriuchi, S. (1981): Hydrolysis of glucosylsucrose and maltosyl-sucrose by rat intestinal disaccharidases. Food and Nutrition (in Japanese), 34, 133-137.

6) Goda, T., and Hosoya, N. (1983): Hydrolysis of palatinose by rat intestinal sucraseisomaltase complex. Food and Nutrition (in Japanese), 36, 169-173.

7) Yoshizawa, S., Moriuchi, S., and Hosoya, N. (1975): The effect of maltitol on rat intestinal disaccharidases. J. Nutr. Sci. Vitaminol., 21, 31-37.

8) Oku, T., Tokunaga, T., and Hosoya, N. (1984): Nondigestibility of a new sweetener, Neosugar, in the rat. J. Nutr., 114, 1574-1581.

9) Lyon, I., and Crane, R. K. (1966): Studies on transmural potentials in vitro in relation to intestinal absorption. Biochim. Biophys. Acta, 112, 278-291.

10) Himukai, M., and Hoshi, T. (1980): Mechanisms of glysyl-L-leucine uptake by guinea pig small intestine; Relative importance of intact-peptide transport. J. Physiol., 302, 155-169.

11) Igarashi, Y., Saito, Y., Himukai, M., and Hoshi, T. (1976): Interpretation of disaccharide dependent electrical potential difference in the small intestine. Jpn. J. Physiol., 26, 79-92.

12) Dahlqvist, A. (1964): Method for assay of intestinal disaccharidases. Anal. Biochem., 7, $18-25$.

13) Lowry, O. H., Rosebrough, N. J., Farr, A, L., and Randall, R. J. (1951): Protein measurement with Folin phenol reagent. J. Biol. Chem., 193, 265-275.

14) Deren, J. J., Broitman, S. A., and Zamcheck, W. (1967): Effect of diet upon intestinal disaccharidases and disaccharide absorption. J. Clin. Invest., 46, 186-195.

15) Grey, G. M., and Santiago, N. A. (1966): Disaccharide absorption in normal and diseased human intestine. Gastroenterology, 51, 489-498.

16) Yamada, K., Bustamante, S., and Koldovsky, O. (1981): Time and dose dependency of intestinal lactase activity in adult rat on starch intake. Biochim. Biophys. Acta, 676, $108-112$.

17) Leichter, J., Goda, T., Bhandari, S. D., Bustamante, S., and Koldovsky, O. (1984): Relation between dietary-induced increase of intestinal lactase activity and lactose digestion and absorption in adult rats. Am. J. Physiol., 247, G729-735. 